ECCOMAS

Proceedia
COMPDYN 2021

$8^{\text {th }}$ ECCOMAS Thematic Conference on Computational Methods in Structural Dynamics and Earthquake Engineering M. Papadrakakis, M. Fragiadakis (eds.)

\title{
A FRAMEWORK FOR THE ASSESSMENT OF SEISMIC DAMAGE SCENARIOS IN THE EMILIA ROMAGNA REGION, ITALY
}

\author{
Elena Simoni ${ }^{1}$, Nicola Buratti ${ }^{2}$, and Claudio Mazzotti ${ }^{2}$ \\ ${ }^{1}$ DICAM - University of Bologna \\ Via Risorgimento 2, Bologna \\ e-mail: elena.simoni8@unibo.it \\ ${ }^{2}$ DICAM - University of Bologna \\ Via Risorgimento 2, Bologna \\ \{nicola.buratti, claudio.mazzotti\}@unibo.it
}

\begin{abstract}
In the immediate aftermath of an earthquake, it is essential that emergency plans and damage scenarios are available so that civil protection agencies and risk-management organizations can detect and contain critical situations. These tools rely on the knowledge of the specific features of the potentially affected area, both in terms of intrinsic characteristics (e.g. morphology, near surface geology, etc.) and of elements at risk (e.g. building typologies, population distribution, etc.). All these pieces of information are combined in seismic-risk or damage scenario assessment procedures. This paper presents a framework developed for estimating seismic damage scenarios for the Emilia Romagna region in Northern Italy. Models for estimating ground-motion shake maps, based on regional attenuation relationships, spatial correlation models and soil data are first presented. These maps, which are computed considering different ground-motion intensity measures, are then combined with data on the spatial distribution of buildings, and fragility models. In order to consider the different sources of uncertainty, i.e. ground-motion intensity, definition of the fragility models, etc., a Monte Carlo simulation approach is used for estimating the distribution of buildings with different damage levels in each municipality. Finally, the paper presents comparisons with damage data observed after the 2012 Emilia earthquake.
\end{abstract}

Keywords: Damage scenarios, Fragility assessment, Shake maps, Spatial correlation, Emilia earthquakes. 


\section{INTRODUCTION}

Seismic risk assessment has the objective of identifying and highlighting the most vulnerable areas in a territory, and thus providing data to limit as much as possible earthquake-induced losses (e.g. economical, human lives, building stock, etc.). To this aim, damage scenarios can be estimated, both at national and regional scales. They are defined by studying past earthquake data in order to estimate the probability of exceeding different damage states in buildings and to quantify the expected losses. Up to date, there are many examples on how to derive damage scenarios, either based on site-specific analyses [1-5] or on larger-scales assessments [6]. After the 2012 earthquake studies have been focused on the Emilia-Romagna region [3,7]. Verderame et al. derived damage scenarios for reinforced concrete buildings and fragility curves were derived combining the Response Surface Method with nonlinear static analyses. Meroni et al. instead adopted the EMS-98 vulnerability classes definition to characterize the regional building stock and expressed its fragility in terms of macroseismic intensity.

The most commonly adopted procedures for the assessment of damage scenarios first require the identification of building types and the characterization of the building stock at the considered scale (i.e. urban, regional, national). In Italy the only complete catalog of the built heritage is the national Census, updated every ten years by the National Institute of Statistics (ISTAT). This survey, however, has the objective of mapping demographics and thus is very poor in terms of structural details of the investigated buildings. Nevertheless, some data are available concerning structural materials, number of stories and age of construction. Afterwards, estimates of the ground-motion intensity are needed. These are often given in the form of shakemaps, i.e. maps providing the spatial distribution of the values of a ground-motion Intensity Measure (IM). Finally, the effects of an earthquake on buildings are predicted combining data from shake maps and fragility models. These latter define the probability of exceeding a certain damage level as a function of the ground-motion intensity. Depending on the methodology employed for their derivation, fragility models can either be (i) empirical when obtained by fitting statistical models to observational data; (ii) analytical when calibrated upon numerical analyses on structural models; (iii) experts' judgement-based when estimated though experts' opinions.

Existing works $[3,8]$ rely on already computed maps to derive vulnerability and exposure models. This study, however, wants to present a comprehensive approach in the definition of damage scenarios for the portion of the Emilia region affected by the 2012 Earthquakes. The adopted computational procedure for the derivation of shake maps is derived by literature studies but relies on specific attenuation relationships calibrated on the available ground motion recordings from the Emilia 2012 earthquakes. Fragility models, which are also specific for the context under consideration, are combined with the ground motion intensity and building distributions through a Monte Carlo simulation approach. This methodology allows to evaluate the damage distribution for each municipality in the area of interest. Outputs obtained with this procedure are then compared with the actual damage distribution observed after the 2012 Emilia earthquakes.

\section{SHAKE MAPS FOR THE 2012 EMILIA EARTHQUAKES}

Shake maps provide a graphical representation of the ground shaking intensity, described by means of an IM, and describe its distribution in an area affected by a seismic event. In the approach adopted here, the ground-motion intensity is first estimated for a regularly spaced grid by means of an attenuation relationship. These values are then combined with data for groundmotion recording stations using a spatial correlation model. The main steps of the procedure, as well as the models adopted, are described in the following. 


\subsection{The 2012 Emilia earthquakes}

In May 2012, the provinces of Modena, Bologna and Ferrara, in northern Italy, were affected by a sequence of moderate seismic events which culminated in two main shocks on the $20^{\text {th }}$ and $29^{\text {th }}$ May, with moment magnitude equal to 6.1 and 6.0 [9], respectively. Ground-motion's data recorded during this seismic sequence was used to fit ground-motion attenuation models. Only the events with $\mathrm{Mw} \geq 5$ were considered to this purpose. Furthermore, since, as discussed in the following Section, the attenuation relationship's form adopted requires the definition of the geometry of the fault rupture plane, shocks for which this information was not available were excluded. Based on these criteria the four events listed in Table 1 were selected.

\begin{tabular}{|c|c|c|c|c|c|c|c|}
\hline Event & Date & Municipality & $\begin{array}{c}\text { Latitude } \\
{\left[^{\circ}\right]}\end{array}$ & $\begin{array}{c}\text { Longitude } \\
{\left[{ }^{\circ}\right]}\end{array}$ & $\begin{array}{l}\text { Depth } \\
{[\mathrm{Km}]}\end{array}$ & $\mathrm{Mw}$ & $\begin{array}{l}\mathrm{GM} \\
\text { records }\end{array}$ \\
\hline $\begin{array}{r}20^{\text {th }} \text { May } \\
\text { main shock }\end{array}$ & $\begin{array}{c}2012-05-20 \\
02: 03: 50\end{array}$ & $\begin{array}{l}\text { Finale } \\
\text { Emilia }\end{array}$ & $\begin{array}{c}44.8955 \\
0\end{array}$ & 11.26350 & 9.5 & 6.1 & 260 \\
\hline $\begin{array}{r}29^{\text {th }} \text { May } \\
\text { main shock }\end{array}$ & $\begin{array}{c}\text { 2012-05-29 } \\
07: 00: 02\end{array}$ & Medolla & $\begin{array}{c}44.8417 \\
0\end{array}$ & 11.06570 & 8.07 & 6 & 284 \\
\hline $\begin{array}{l}29^{\text {th }} \text { May } \\
\text { aftershock }\end{array}$ & $\begin{array}{c}2012-05-29 \\
10: 55: 56\end{array}$ & Cavezzo & $\begin{array}{c}44.8652 \\
0\end{array}$ & 10.97950 & 4.35 & 5.5 & 182 \\
\hline $\begin{array}{l}29^{\text {th }} \text { May } \\
\text { aftershock }\end{array}$ & $\begin{array}{c}2012-05-29 \\
11: 00: 22\end{array}$ & $\begin{array}{c}\text { San } \\
\text { Possidonio }\end{array}$ & $\begin{array}{c}44.8660 \\
0\end{array}$ & 10.97630 & 7.2 & 5.5 & 149 \\
\hline
\end{tabular}

Table 1: Main information about the select events from the $20^{\text {th }}$ and $29^{\text {th }}$ May Emilia 2012 sequence [9].

\subsection{Ground-motion attenuation relationships}

Attenuation relationships are empirical statistical models that define the dependency of the values of an IM on seismological parameters as magnitude and source-to-site distance and other parameters such as type of soil at the site, style of faulting, bedrock depth, etc. The functional form employed in this study is

$$
\ln (I M)=c_{1}+c_{2} \cdot M+c_{3} \cdot \ln \left(\sqrt{R^{2}+c_{4}^{2}}\right)+c_{5} \cdot \ln (R+25)+s f+\sigma_{w} \varepsilon_{w}+\sigma_{b} \varepsilon_{b}
$$

where $\ln (I M)$ is the natural logarithm of PGARotD50, defined according to Boore et al. [10] as the $50^{\text {th }}$ percentile of the PGA values obtained rotating the acceleration horizontal components from 0 to $180^{\circ}, M$ is the moment magnitude, $R$ is the Joyne-Boore distance in $\mathrm{km}, s f$ is a term describing site amplification effects, $\varepsilon_{w}$ and $\varepsilon_{b}$ are intra- and inter-event standard normal error terms, respectively, $\mathrm{c}_{1}, \ldots, \mathrm{c}_{5}$ are unknown regression coefficients, $\sigma_{\mathrm{w}}$ and $\sigma_{\mathrm{b}}$ are unknown standard deviations associated to the intra- and inter-event variability, respectively. The term $s f$ is defined as:

$$
s f=\mathrm{c}_{6} \cdot S_{B}+\mathrm{c}_{7} \cdot S_{C}+\mathrm{c}_{8} \cdot S_{D}
$$

where $\mathrm{c}_{6}, \ldots, \mathrm{c} 8$ are unknown regression coefficients and $S_{B}, S_{C}$ and $S_{D}$ are dummy variables representing different soil classes. In particular, $\mathrm{S}_{\mathrm{B}}$ is 1 for soil class $\mathrm{B}$ and 0 otherwise, $\mathrm{S}_{\mathrm{C}}$ is 1 for soil class $\mathrm{C}$ and zero otherwise and $\mathrm{S}_{\mathrm{D}}$ is 1 for soil class $\mathrm{D}$ and 0 otherwise. The definition of soil classes is based on the Italian Building Code [11]. The values of the unknown coefficients in Equations (1) and (2) are estimated by means of nonlinear mixed effects regression 
models, using recorded acceleration data from all the ground-motion recording stations at a distance shorter than $200 \mathrm{~km}$ from the epicenters of the earthquakes listed in Table 1. This table also reports the number of ground-motion records associated with each event. The model in Eq. (1) incorporates fixed and random effects. The former are parameters assumed as constant over the different groups of observations (each earthquake is a group), while random effects are random variables that assume a different value for each earthquake. The obtained attenuation relationship is plotted in Fig. 1 together with PGARotD50 data for the four events considered. Random effects do not vary significatively for each separate event which means that the between-event standard deviation is quite limited.

(a)

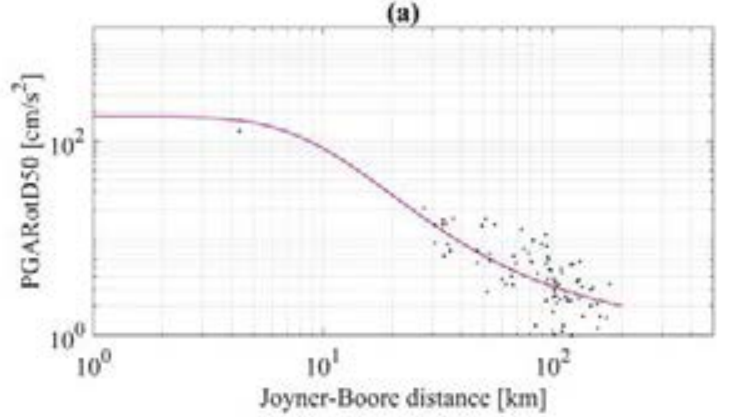

(c)

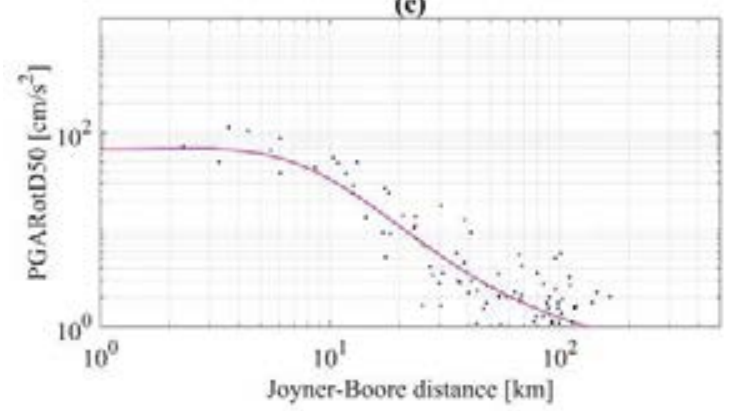

(b)

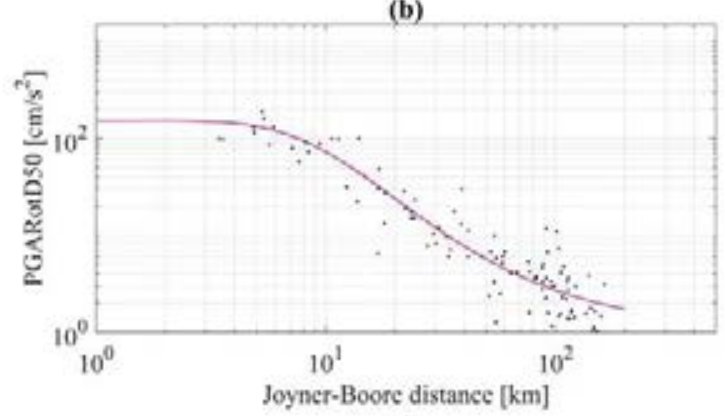

(d)

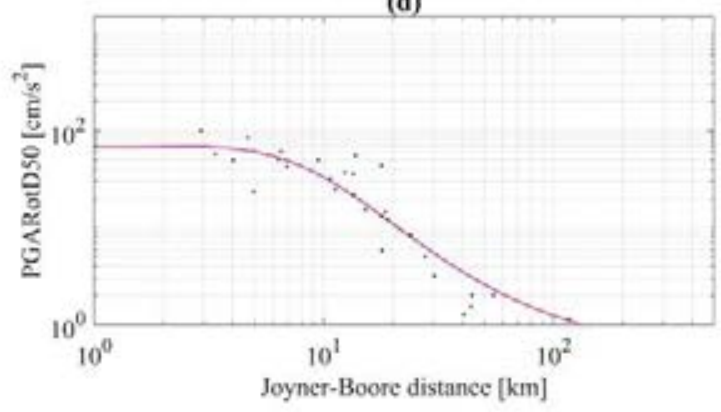

Fig. 1 - Attenuation relationship in logarithmic scale referred to an ideal rigid soil (class A). Blue dots are PGARot50 recordings for each event in terms of Joyner-Boore distance that have been referred to an equivalent soil type A. Event a) and b) are the main shocks of the $20^{\text {th }}$ and $29^{\text {th }}$ May respectively, while c) and d) are the $29^{\text {th }}$ May aftershocks.

\subsection{Spatial correlation models}

Spatial correlation models must be defined for the computation of shake maps. In fact it has been observed that ground motion IM values are spatially correlated [12-14]. Clearly this correlation is not accounted for in the IM prediction given by attenuation relationships, which is for this reason called unconditioned. Shake maps instead combine the unconditioned distribution and recorded values, thus providing a conditioned distribution. Spatial correlation models were defined based on empirical semivariograms for the residuals obtained from the regression analysis carried out to fit the attenuation model. By visual comparison of different models, the spherical model was selected to fit the sample semivariograms. This model is defined as:

$$
\gamma(h)=\left\{\begin{array}{cc}
\frac{3 h}{2 a}-\frac{1}{2}\left(\frac{h}{a}\right)^{3} & \text { for } 0 \leq h \leq a \\
1 & \text { for } h>a
\end{array}\right.
$$


being $a$ the range and $h$ the separation distance, whereas $\gamma(h)$ is the semivariance. Spatial correlation is then obtained by subtracting the semivariance from unity.

\subsection{Shake maps computation}

As already mentioned in the previous sections, shake maps provide estimates of the spatial distribution of a ground motion IM over a certain area. Since a large number of ground-motion recordings is required in order to have reliable estimates, only the main events from the $20^{\text {th }}$ and $29^{\text {th }}$ May are considered from now on. Furthermore, it is also assumed that these events are those that contributed the most to building damage. Shake maps combine predictions from attenuation relationships, spatial correlation models and recorded IM values to derive estimates on a regular grid. The computational procedure adopted is derived from Bradley [13] and Worden et al. [15] and relies on the MVN theory. It is based on the hypothesis that the distribution of the natural logarithm of the IM produced by the earthquake $e$ at site $s$, conditioned upon a set of $N_{S M S}$ ground motion recordings, $\ln \left(I M_{e s}\right) \mid \ln \left(I M_{e S M S}\right)$, follows a multivariate normal distribution with mean value $\mu \ln (I M e s) \mid \ln (I M e S M S)$ and standard deviation $\sigma \ln (I M e s) \mid \ln (I M e S M S)$ :

$$
\ln \left(I M_{e S}\right) \mid \ln \left(I M_{e S M S}\right) \sim N\left(\mu_{\ln \left(I M_{e S}\right)}\left|\ln \left(I M_{e S M S}\right), \sigma_{\ln \left(I M_{e S}\right)}^{2}\right| \ln \left(I M_{e S M S}\right)\right.
$$

The mean value of this distribution can be estimated as:

$$
\mu_{\ln \left(I M_{e S}\right) \ln \left(I M_{e S M S}\right)}=\mu_{\ln \left(I M_{e S}\right)}+\boldsymbol{\Sigma}_{\ln \left(I M_{e S}\right), \ln \left(I M_{e S M S}\right)} \boldsymbol{\Sigma}_{\ln \left(I M_{e S M S}\right), \ln \left(I M_{e S M S}\right)}{ }^{-1} \boldsymbol{\delta}_{W_{e S}}+\delta_{B_{e}}
$$

where $\mu \ln (I M e s)$ is the unconditioned estimate of the mean value of the logarithm of the IM obtained by means of an attenuation relationship, $\delta_{B \mathrm{e}}$ is the inter-event residual, $\boldsymbol{\delta}_{W \text { es }}$ is a vector of intra-event residuals with NSMS components, $\Sigma_{\ln (I M e S M S), \ln (I M e S M S}$ is a variance-covariance matrix whose general term is defined as:

$$
\left(\boldsymbol{\Sigma}_{\ln \left(I M_{e S M S}\right), \ln \left(I M_{e S M S}\right)}\right)_{i, j}=\rho_{i, j} \sigma_{\mathrm{W}}^{2} ; \quad \mathrm{i}=1, \ldots, N_{S M S} ; \mathrm{j}=1, \ldots, N_{S M S}
$$

being $\rho_{i, j}$ the spatial correlation between the IM values at the $i$-th and $j$-th ground motion recording stations and $\sum_{\ln (I M e s), \ln (I M e S M S}$ is a variance-covariance matrix defined as:

$$
\left(\boldsymbol{\Sigma}_{\ln \left(I M_{e S}\right), \ln \left(I M_{e S M S}\right)}\right)_{1, \mathrm{i}}=\rho_{\mathrm{s}, j} \sigma_{\mathrm{W}}^{2} ; \mathrm{j}=1, \ldots, N_{S M S}
$$

Intra- and inter-event residuals are here determined by means of the attenuation relationship and are assumed to be normally distributed with null mean. The variance in Eq. (4) is computed as:

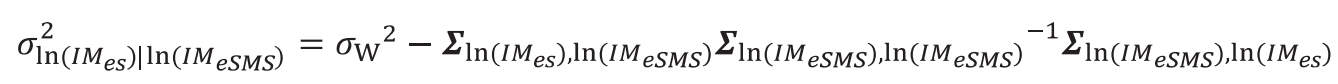

Maps are computed for one event at time. In Figure 2 and the spatial distribution of PGARotD50 derived with the methodology just described is presented for the main shock of the $29^{\text {th }}$ of May 2012, while Figure 3 shows the spatial distribution of the variance associated. 


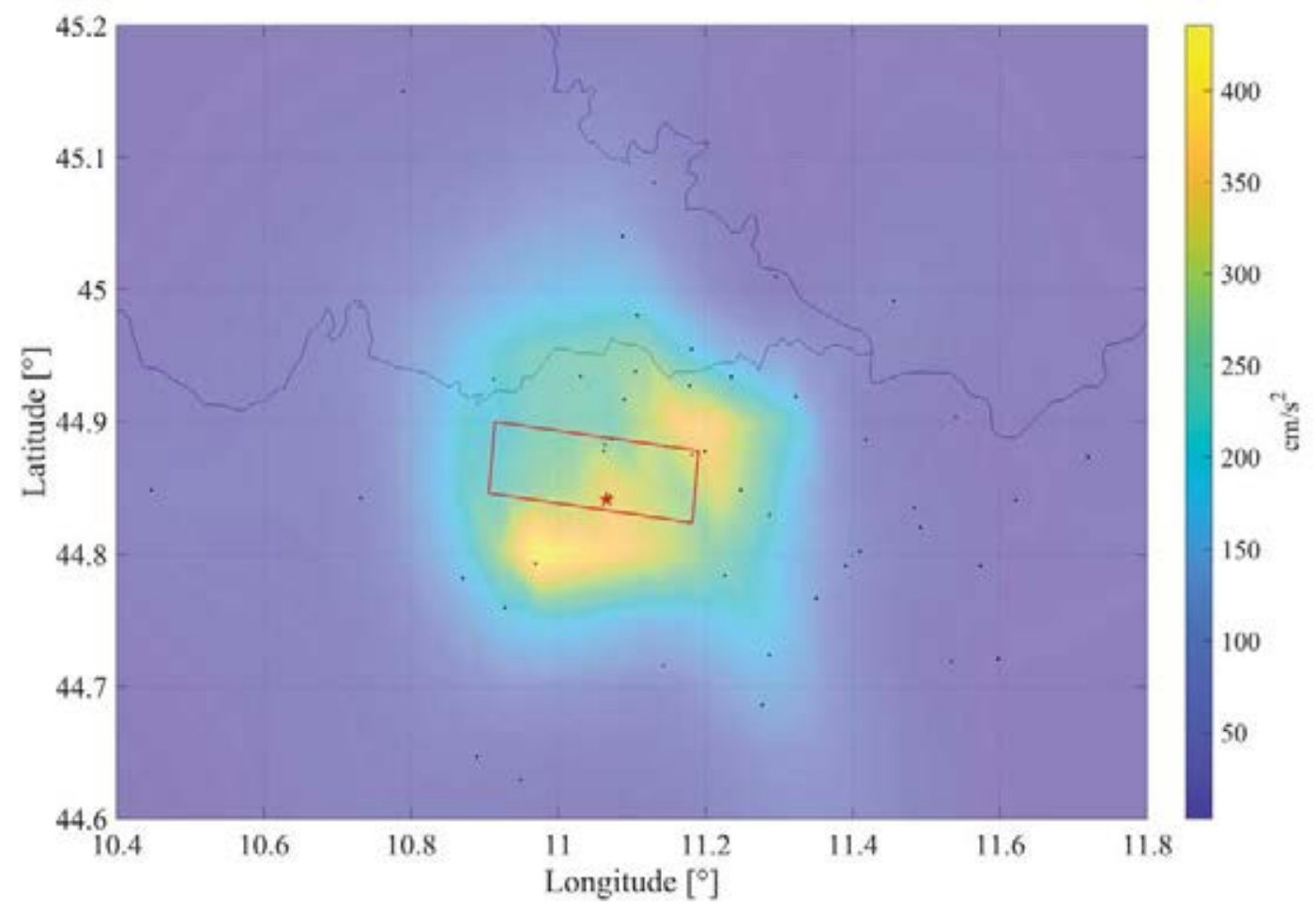

Fig. 2 - Shake map for the $29^{\text {th }}$ of May 2012 event in terms of median PGARotD50 assuming uniform soil type C. Black dots are ground motion recording stations. The red polygon indicates the surface projection of the fault plane while the star symbol represents the position of the epicenter.

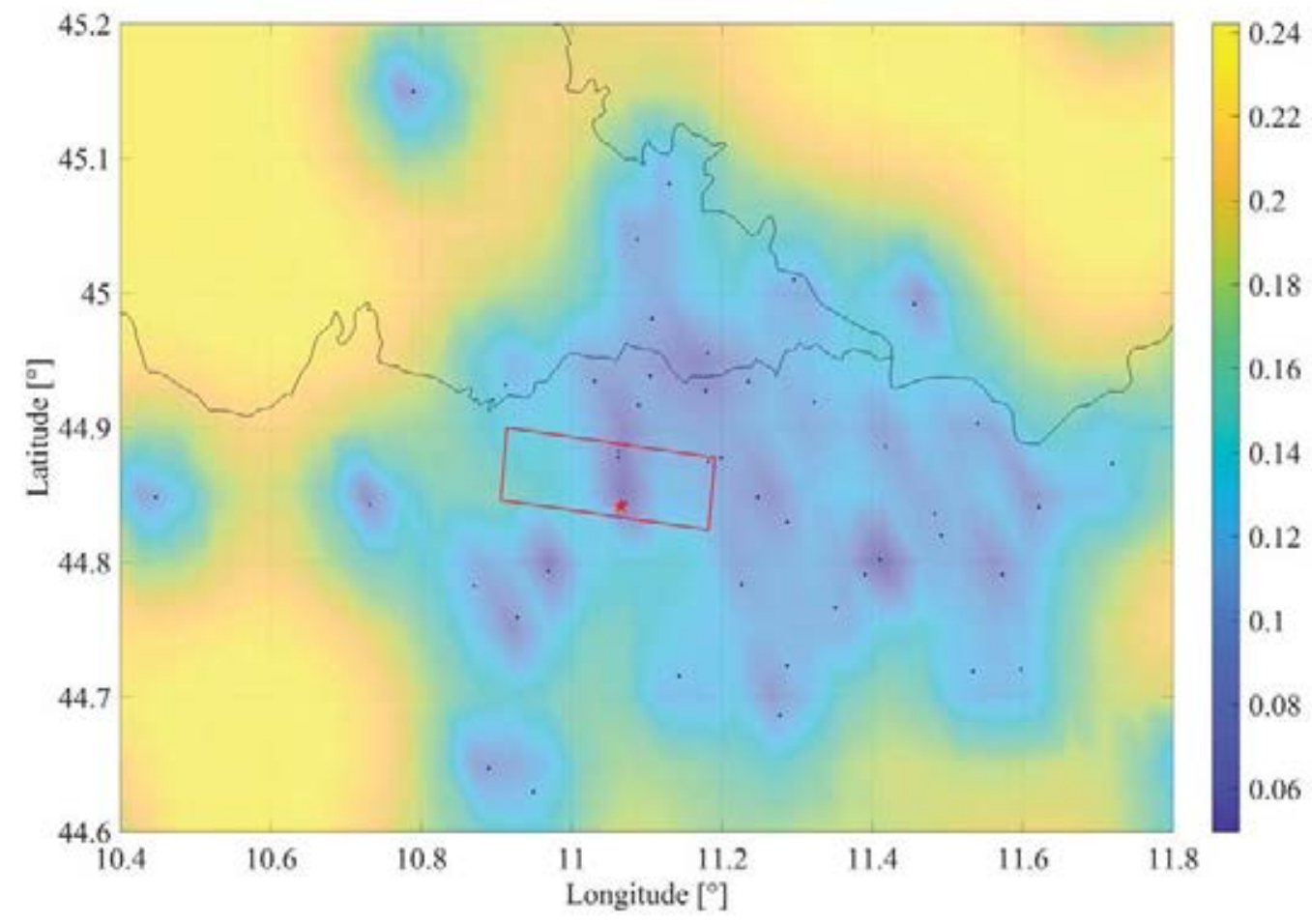

Fig. 3 - Spatial distribution of the variance associated with the $\log 10$ (PGARotD50) estimate. Variance is null in correspondence of ground motion recordings stations (black dots). The red polygon indicates the surface projection of the fault plane while the star symbol represents the position of the epicenter. 


\section{FRAGILITY MODELS}

Fragility is generally referred to as the probability of exceeding a specific damage state conditioned to a certain ground motion IM value. Damage probability matrices (DPMs) describe fragility as a discrete quantity, relating the number of buildings with damage levels to some defined intervals of values of the IM [16,17]. To express fragility as a continuous function, parametric curves are often adopted. They represent the cumulative distribution function of the exceeding probability for the considered damage states. For the Emilia 2012 earthquakes a few specific models are available, both for masonry and reinforced concrete residential buildings. To carry out a damage scenario simulation, fragility models have to be consistent not only in terms of the building typology they refer to, but also in terms of adopted damage scale and ground motion IM considered. The following Sections describe the fragility models adopted in the present work; three different models for Reinforced Concrete (RC) and two models for unreinforced masonry structures.

\subsection{Fragility curves for unreinforced masonry structures}

The characteristics of existing unreinforced masonry buildings are highly dependent on the quality and type of materials that can be found in a specific geographical area. For this reason, only models that have been derived from the Emilia-Romagna region residential masonry buildings were employed in this study. The first model used has been recently proposed by Ioannou et al. [18], and it is based on the analysis of damage data from the 2012 Emilia earthquake obtained from post-earthquake surveys. This dataset, however, is biased towards damaged buildings and the census [19] was used to complete the building stock with the undamaged buildings. Data was aggregated at the level of municipalities. It has often been highlighted $[18,20,21]$ that this practice, common for empirical fragility assessment, reduces the level of detail in the building typology definition. The ground motion intensity was estimated using the attenuation model proposed by Bindi et al. [22]. Ioannou et al. then define several statistical models that relate 5 damage levels derived from EMS-98 to PGA, to the construction material (masonry, RC and other), to ground failure, and to the construction age. In the present study the model for masonry buildings was used.

The second set of curves was specifically derived by the authors in the present paper, based on statistical analysis of observational damage data. In a similar manner to the approach adopted in Ioannou et al., a complete database for masonry buildings, accounting for both the damaged and undamaged population, was obtained by combining information from post-earthquake surveys and census. The two sources were joined using the nearest neighbor criterion, i.e. for each post-earthquake survey form the nearest census building was deleted so that single entities are not double counted. Ground motion PGA values were estimated using maps derived according to the procedure described in Section 2. The fragility models obtained are based on logistic ordinal models, to avoid overlapping of fragility curves. The proportional odds assumption was introduced, thus considering that the slope of the curves is constant over the different damage levels. Specifically, a link logit function was used, and the covariate of the models was assumed to be constituted by the natural logarithm and squared natural logarithm of PGA, as shown in Eq. (9).

$$
\Phi^{-1}\left(p_{i, j}\right)=\beta_{0, j}+\ln \left(I M_{i}\right) \beta_{1}+\ln \left(I M_{i}\right)^{2} \beta_{2}
$$

being $\beta_{0, j}$ the intercept for each damage level, while $\beta_{1}$ and $\beta_{2}$ represent the slopes, constant among the different damage states. The two considered fragility models are shown in Fig. 4. 


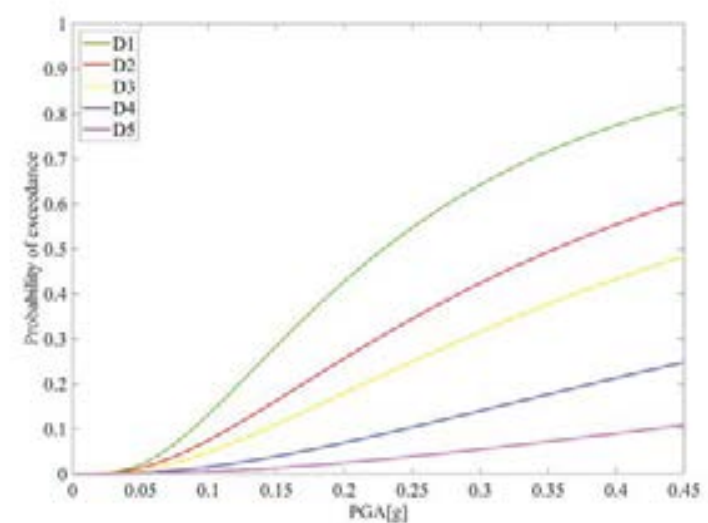

(a)

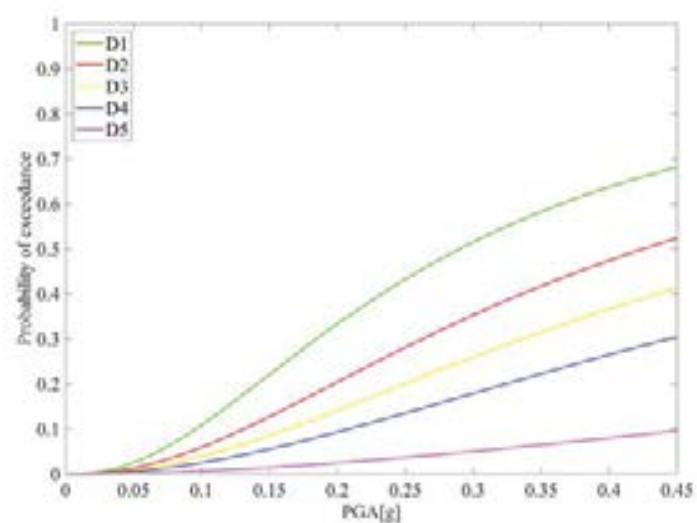

(b)

Fig. 4 - (a) Ioannou et al. [18] fragility curves and curves from the present work (b). Fragility is expressed in terms of PGA $[\mathrm{g}]$ for five different damage states.

\subsection{Fragility curves for $R C$ buildings}

The first fragility model used in the present study was proposed by Verderame et al. [3]. These fragility curves were obtained by modeling infilled RC frames with 2 and 4 stories. Their geometry was defined after a detailed analysis of the damage distribution and of the residential building stock in some municipalities of the Emilia region while their structural detailing was derived referring to the post-1945 Italian regulations for RC buildings [23]. The capacity of these models was evaluated by means pushover analysis, while the IN2 method was used to estimate the displacement demand [24]. To derive fragility curves, damage thresholds expressed in terms of displacement capacity were first defined, while the variability of material characteristics or capacity parameters was accounted for by means of Response Surface metamodels. Lognormal fragility curves were obtained in terms of PGA for five different damage states, defined according to a mechanical interpretation of the EMS-98 scale [25].

The second fragility model adopted was developed by Salamida and Buratti [26] by applying nonlinear static analysis to study the structural response of 2- and 4-stories infilled RC frames, found to be the most common reinforced concrete residential building type in the Emilia region. Material properties and construction details were defined by means of simulated design, considering the Italian design adopted between 1950 and 1970. Damage states were defined from the EMS-98 scale as in Verderame et al., and fragility curves were calibrated separately for the different directions of application of the seismic action and for distributions of lateral loads Overall fragility curves, were then computed as the mean probability of exceedance for the separate curves.

The third model used was proposed by Secci [27] and was developed through statistical analysis of data on the observed damage on RC buildings from the 2009 L'Aquila earthquake in Italy. For RC buildings it can be assumed that material properties are not strictly related to geography and local construction technologies. Furthermore, while analytical fragility models are generally biased though a very specific building typology, empirical models are able to account for the greater variability found in real buildings in terms of structural performance. Secci employed Bayesian regression to estimate the exceedance probability for five different damage states, based on the EMS-98, as a function of PGA. Damage levels were derived from post-earthquake surveys using the procedure proposed by Rota el a. [28]. The three considered fragility models are shown in Fig.5. 


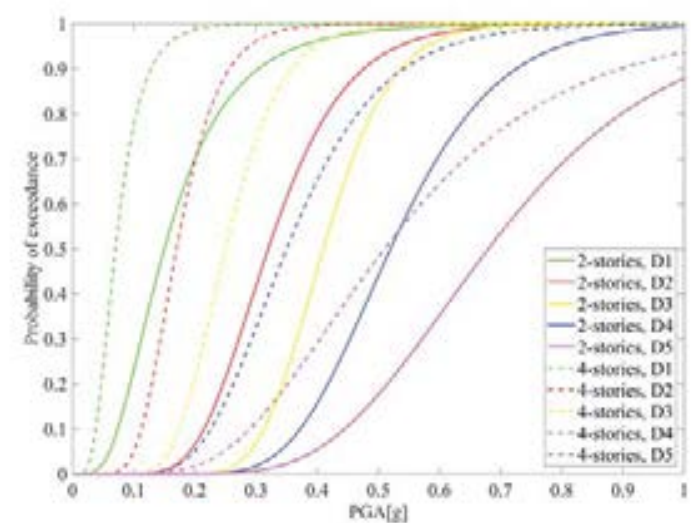

(a)

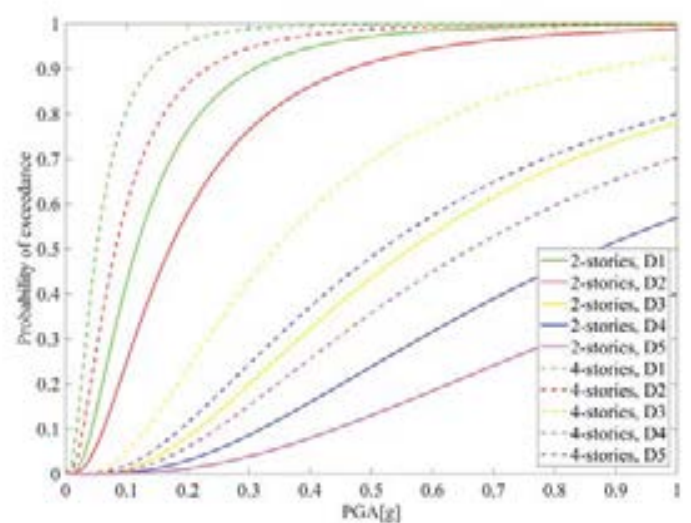

(b)

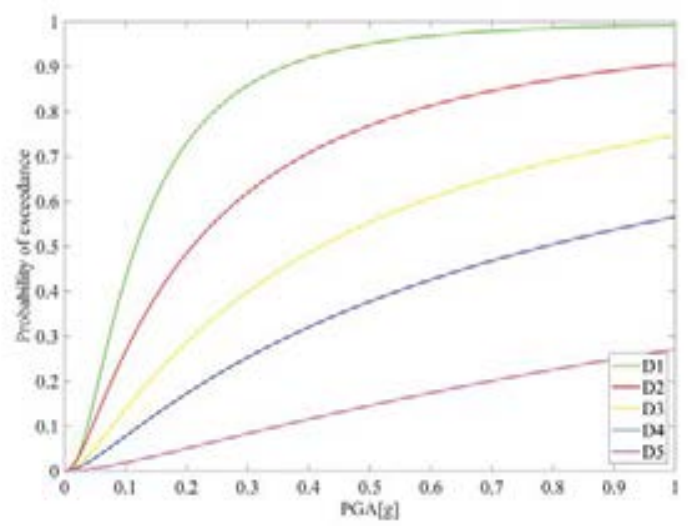

(c)

Fig. 5 - Fragility curves for RC buildings used in the present paper a) Verderame et al. [3], b) Salamida and Buratti [26], c) Secci [27]

\section{SIMULATION OF DAMAGE SCENARIOS}

Damage scenarios are here derived only for municipalities within the epicentral area of the 2012 Emilia earthquake. Information regarding the building stock for each municipality is derived from the 2011 census [19]. The data used concerns geographical coordinates, construction material, age of construction and number of stories.

A Monte Carlo approach is then employed to evaluate a damage scenario in each municipality, for a given earthquake. First, the joint distribution of the ground motion intensity in terms of PGA at the locations of all the $N_{b, k}$ buildings in the $k$-th municipaly is estimated using the procedure described in Section 2. In particular, this distribution can be written as

$$
\ln (\boldsymbol{I} \boldsymbol{M})_{k} \sim N\left(\boldsymbol{M}_{k},\left(\boldsymbol{\Sigma}_{\ln \left(I M_{i}\right), \ln \left(I M_{j}\right)}\right)_{k}\right)
$$

where $\boldsymbol{I} \boldsymbol{M}_{\mathrm{k}}$ is a random vector containing the $N_{b, k}$ ground motion intensities associated to the buildings of the $k$-th municipality, $\boldsymbol{M}_{k}$ is a vector containing the mean values of $\ln \left(\boldsymbol{I} \boldsymbol{M}_{\mathrm{k}}\right)$, and $\left(\Sigma_{\ln \left(I M_{i}\right), \ln \left(I M_{j}\right)}\right)_{k}$ is a variance-covariance matrix. The general element of this matrix is computed as per Eq. (6), though the spatial correlation and the standard deviation are referred to the ground-motion intensities at the locations of the $i$-th and $j$-th building.

The general iteration of the Monte Carlo simulations is then carried out as follows: 
i. A random sample of ground motion intensities is drawn from the distribution defined by Eq. (10).

ii. A fragility model is randomly chosen among those defined in Section 3.1 and Section 3.2 for unreinforced masonry and RC buildings, respectively.

iii. The probability of achieving the different damage levels (as well as no damage) is computed for each building combining data from i. and ii. When either the Verderame et al [3] or the Salamida and Buratti [21] fragility model is selected for RC buildings, the probabilities are computed considering the number of stories of each building (census data).

iv. For each building a damage state is define by comparing a random number drawn from a uniform PDF in the interval $[0,1]$ to the probabilities computed at step iii.

A number of 10000 simulations is carried out for each municipality. In the following, results are presented separately for masonry and $\mathrm{RC}$ residential buildings.

\subsection{Analysis of results for unreinforced masonry structures}

To represent the simulation outcomes in a compact notation, histograms are used to visualize the mean number of buildings with the different damage levels, in contrast to damage data observed after the 2012 Emilia earthquakes.

Fig. 6, compares the distribution of damage in masonry buildings with reference to municipalities located within $10 \mathrm{~km}$ from the epicenter. It can be noted that buildings with low damage levels, such as $\mathrm{D}_{0}$ or $\mathrm{D}_{1}$ are overestimated by the simulation. To further investigate the simulated damage scenarios, municipalities outside the immediate epicentral area are considered, located at a distance larger than $10 \mathrm{~km}$ but still not further than $30 \mathrm{~km}$. These areas are expected to be subjected to strong ground-motions, according to the computed shake map, but were not highly damaged, according to post-earthquake surveys. As shown in Fig. 7, in these municipalities, simulations predict higher damage levels than those observed. Damage scenarios, in fact, rely on fragility models that are calibrated on the whole observed damage database, thus, representing a mean trend in the damage observations among municipalities. This implies that this type of approach is better employed when evaluating the expected damage on a regional scale, while if used to derive damage scenarios at the municipality level, this could lead to underestimation or overestimation of the expected damage distribution.
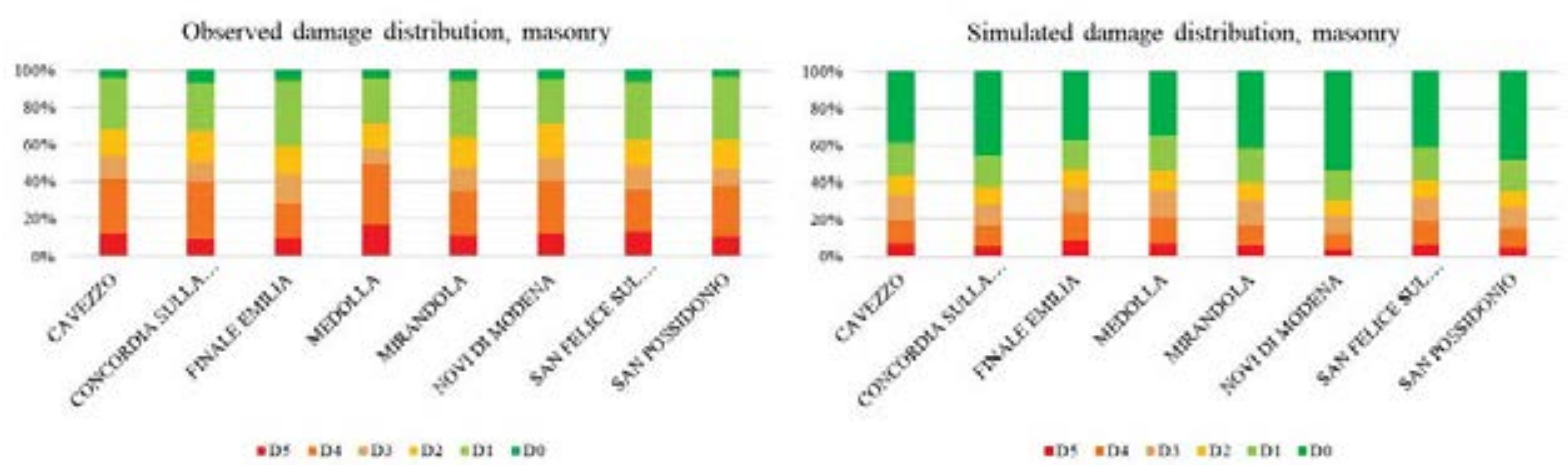

Fig. 6 - Comparison between observed (right) and mean values of the simulated (left) damage distribution for masonry buildings for municipalities in the immediate epicentral area (distance from epicenter $<10 \mathrm{~km}$ ). 

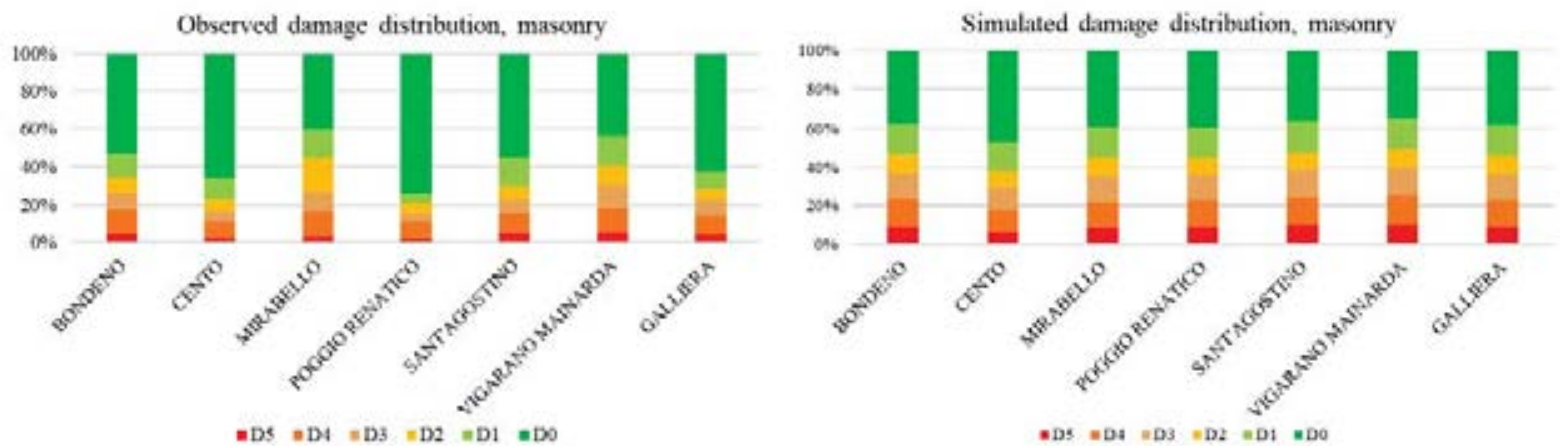

Fig. 7 - Comparison between observed (right) and mean values of the simulated (left) damage distribution for masonry buildings for municipalities in the slightly further epicentral area $(10 \mathrm{~km}<$ distance from epicenter $<30$ $\mathrm{km})$.
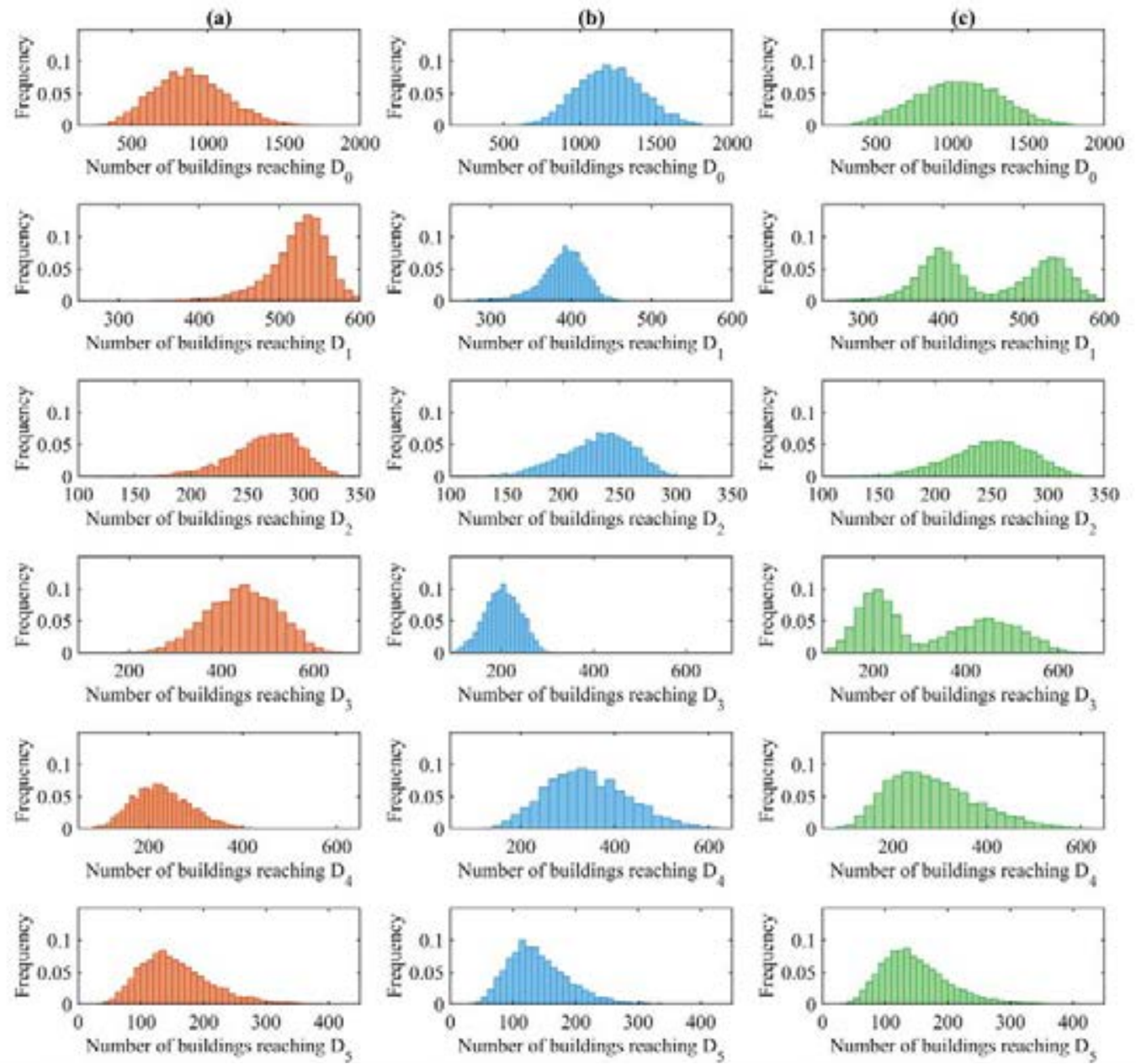

Fig. 8 - Histograms representing the distribution of the different damage levels among the 10000 simulations for the municipality of Mirandola. The a) column figures represent the contribution given by Ioannou et al. [18] fragility model, the b) column is the one given by the fragility model presented in the current paper, while c) represents the totality of the simulations. 

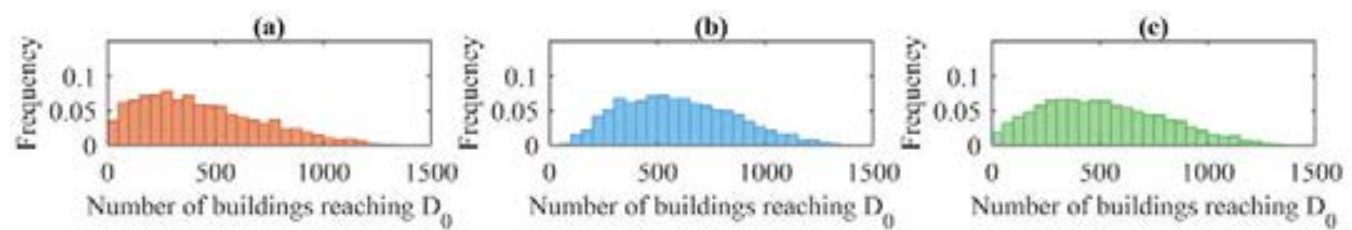

Number of buildings reaching $\mathrm{D}_{0}$
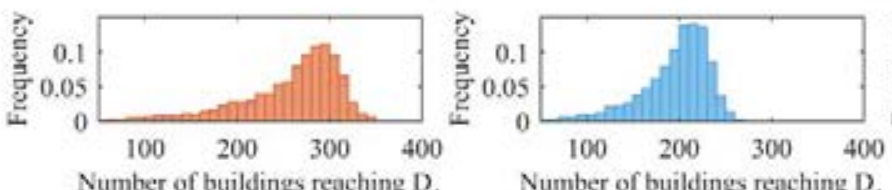

Number of buildings reaching $\mathrm{D}_{0}$
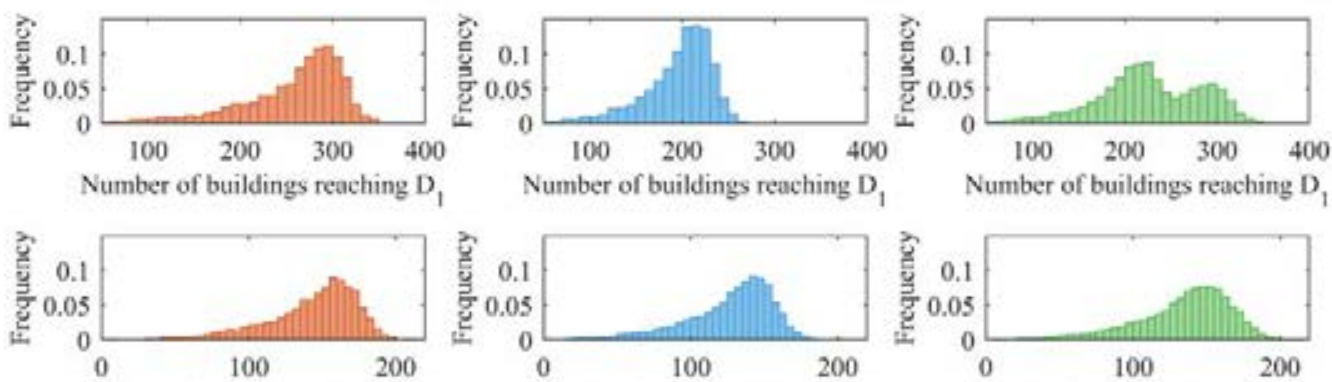

Number of buildings reaching $\mathrm{D}_{2}$

Number of buildings reaching $\mathrm{D}_{2}$
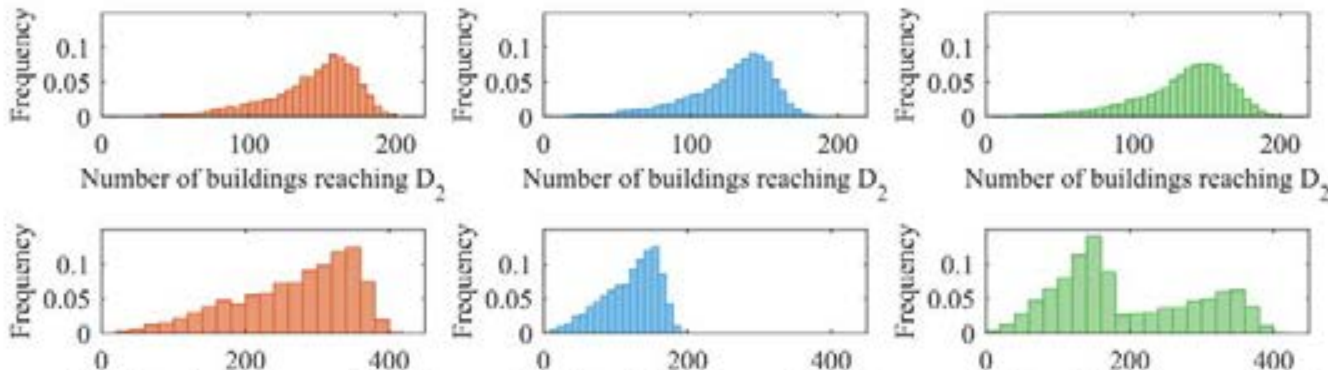

Number of buildings reaching $\mathrm{D}_{3}$

Number of buildings reaching $\mathrm{D}_{3}$

Number of buildings reaching $\mathrm{D}_{2}$
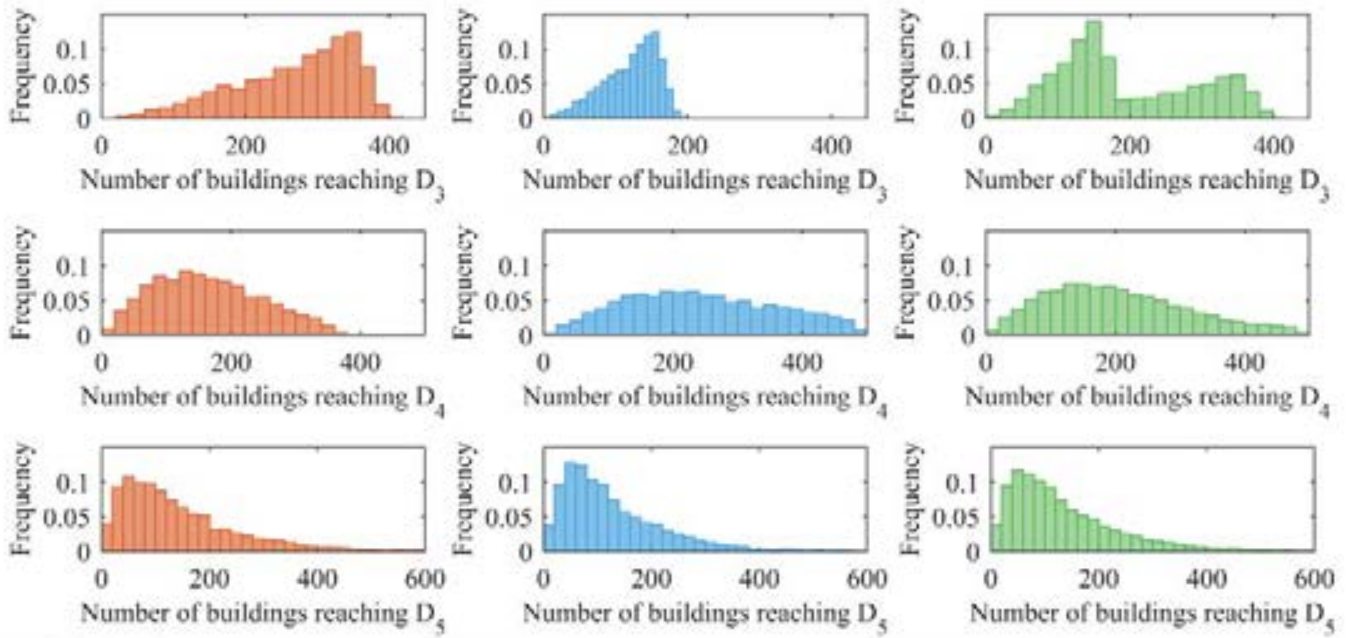

Fig. 9 - Histograms representing the distribution of the different damage levels among the 10000 simulations for the municipality of Sant'Agostino. The a) column figures represent the contribution given by Ioannou et al. [18] fragility model, b) is the one given by the fragility model presented in the current paper, while c) represents the totality of the damage levels distribution accounting for both models.

The variability of the simulation results is analyzed in Fig. 8 and Fig. 9 for the municipalities of Mirandola (MO) and Sant'Agostino (FE). It is evident, from both figures that buildings reaching $\mathrm{D}_{0}$ have a high variability compared to other damage states. From the figures above, for levels $\mathrm{D}_{1}$ and $\mathrm{D}_{3}$ the two fragility models produce different results, while other damage states are quite coherent with each other.

\subsection{Analysis of the results for $R C$ buildings}

Results for reinforced concrete buildings, differently than those obtained for masonry structures, rely on both empirical and analytical fragility models. Analytical models are highly dependent on the assumptions introduced in the definition of structural models and can be very accurate in describing the behavior of that specific typology, while failing to account for the variability that characterizes the actual building stock. Comparison between observed and simulated damage distributions is presented in Fig. 10 for municipalities within $10 \mathrm{~km}$ from the epicenter that sustained significant damage, according to post-earthquake surveys. To further investigate the contribution given by each separate model, simulations are also run considering each fragility model one at time and the so obtained damage distributions are presented for the same municipalities in Fig. 11. 

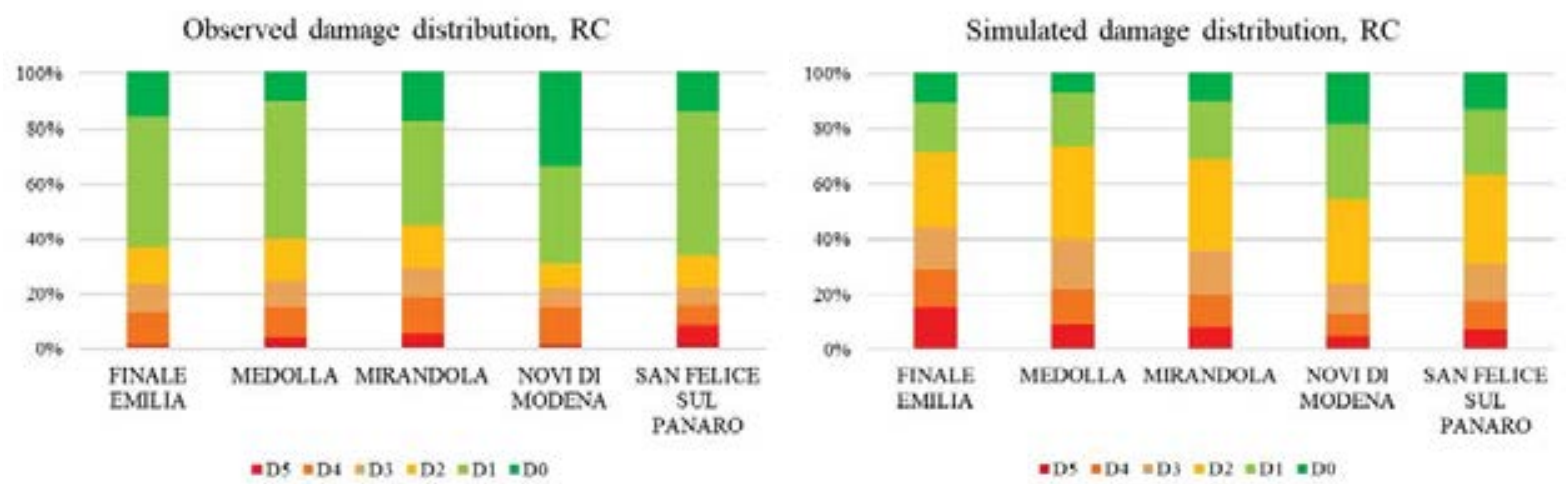

Fig. 10 - Comparison between observed (right) and mean values of the simulated (left) damage distribution for RC buildings for municipalities in the epicentral area (distance from epicenter $<10 \mathrm{~km}$ ).

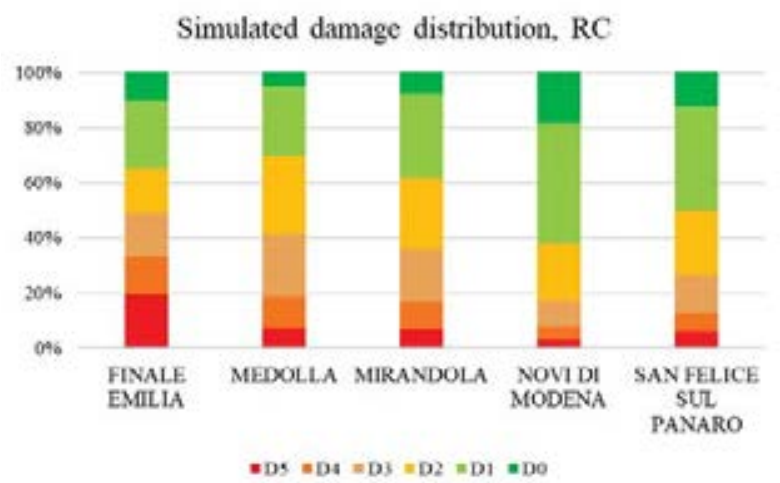

(a)

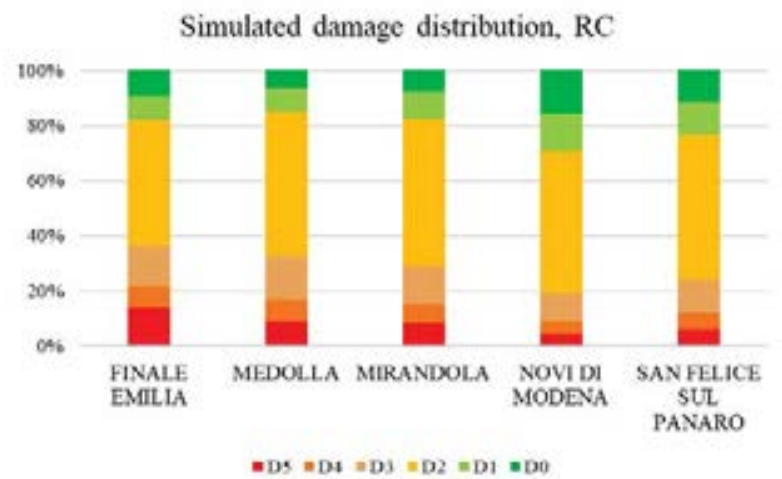

(b)

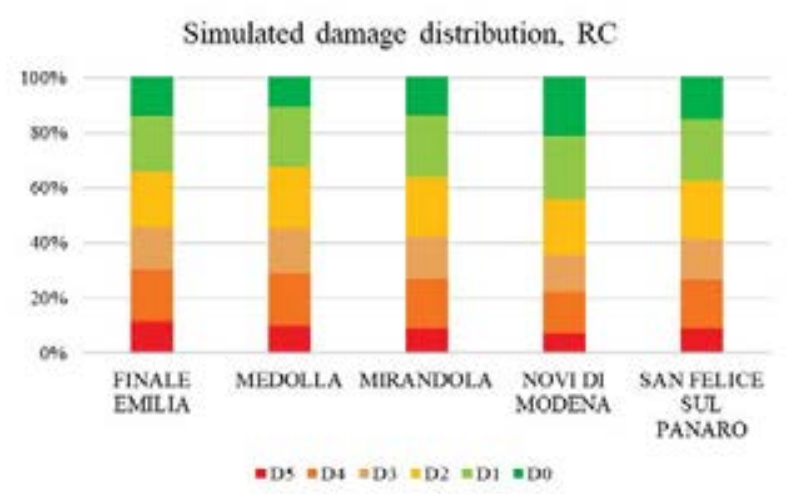

(c)

Fig. 11 - Mean value of the simulated damage distribution adopting either (a) Verderame et al. [3], (b) Salamida and Buratti [21] or Secci [27] fragility models.

Substantial differences can be observed comparing the observed and the simulated damage, both considering all fragility models together and separately. As already mentioned, Verderame et al. [3] and Salamida and Buratti [26] models adopt different sets of fragility curves depending on the height of buildings. To study the reliability of the adopted procedure, the number of stories distribution is analyzed in the subset considered and in the overall building database. First the census (Dat1) and the post-earthquake surveys (Dat2) databases are considered with 
reference to the provinces of Bologna, Modena and Ferrara. Then the combined database (Dat3) is studied. Results are shown in Table 2.

\begin{tabular}{lcccccc}
\hline \multirow{2}{*}{ Database } & $\mathbf{5}$ & $\mathbf{2}$ & $\mathbf{3}$ & $\mathbf{4}$ & $\mathbf{5}$ & $>\mathbf{5}$ \\
\hline Dat1 & $3.45 \%$ & $40.06 \%$ & $26.04 \%$ & $14.95 \%$ & $6.70 \%$ & $8.81 \%$ \\
Dat2 & $29.10 \%$ & $18.14 \%$ & $17.87 \%$ & $14.69 \%$ & $7.96 \%$ & $11.31 \%$ \\
Dat3 & $5.67 \%$ & $38.06 \%$ & $25.22 \%$ & $14.89 \%$ & $6.89 \%$ & $9.19 \%$ \\
\hline
\end{tabular}

Table 2: Percentages with respect to the total of buildings separated for number of stories and database. Dat1 is the census dataset, Dat 2 is the post-earthquake surveys one and Dat 3 is the joint database

\begin{tabular}{lrrrrrrr}
\hline \multicolumn{1}{c}{ Municipality } & N. of stories & \multicolumn{7}{c}{ Dat1 } & & & & & \\
& $\mathbf{1}$ & $\mathbf{2}$ & $\mathbf{3}$ & $\mathbf{4}$ & $\mathbf{5}$ & $>\mathbf{5}$ & Total \# \\
\hline Finale Emilia & $0.00 \%$ & $8.97 \%$ & $16.67 \%$ & $50.00 \%$ & $21.79 \%$ & $2.56 \%$ & 78 \\
Medolla & $0.00 \%$ & $4.65 \%$ & $16.28 \%$ & $51.16 \%$ & $27.91 \%$ & $0.00 \%$ & 43 \\
Mirandola & $3.85 \%$ & $5.68 \%$ & $16.63 \%$ & $31.03 \%$ & $41.38 \%$ & $1.42 \%$ & 493 \\
Novi di Modena & $1.69 \%$ & $2.82 \%$ & $9.60 \%$ & $21.47 \%$ & $60.45 \%$ & $3.95 \%$ & 177 \\
San Felice sul Panaro & $0.00 \%$ & $2.86 \%$ & $1.43 \%$ & $14.29 \%$ & $71.43 \%$ & $10.00 \%$ & 70 \\
\hline
\end{tabular}

\section{Dat2}

\begin{tabular}{lrrrrrrrr}
\multicolumn{1}{c}{ Municipality } & N. of stories & & & & & \\
& $\mathbf{1}$ & $\mathbf{2}$ & $\mathbf{3}$ & $\mathbf{4}$ & $\mathbf{5}$ & $\mathbf{5}$ & \multicolumn{1}{c}{ Total \# } \\
\hline Finale Emilia & $40.63 \%$ & $21.25 \%$ & $16.88 \%$ & $11.88 \%$ & $5.63 \%$ & $0.63 \%$ & 160 \\
Medolla & $40.00 \%$ & $22.22 \%$ & $22.22 \%$ & $14.44 \%$ & $0.00 \%$ & $0.00 \%$ & 90 \\
Mirandola & $30.38 \%$ & $16.46 \%$ & $14.77 \%$ & $16.46 \%$ & $11.18 \%$ & $0.00 \%$ & 474 \\
Novi di Modena & $26.06 \%$ & $28.87 \%$ & $23.94 \%$ & $9.15 \%$ & $4.93 \%$ & $0.00 \%$ & 142 \\
San Felice sul Panaro & $22.22 \%$ & $20.37 \%$ & $39.81 \%$ & $11.11 \%$ & $5.56 \%$ & $0.00 \%$ & 108 \\
\hline
\end{tabular}

\section{Dat3}

\begin{tabular}{lrrrrrrrr}
\multicolumn{1}{c}{ Municipality } & N. of stories & & & & & \\
& $\mathbf{1}$ & $\mathbf{2}$ & $\mathbf{3}$ & $\mathbf{4}$ & $\mathbf{5}$ & $\mathbf{5}$ & Total \# \\
\hline Finale Emilia & $40.12 \%$ & $20.99 \%$ & $17.90 \%$ & $11.73 \%$ & $5.56 \%$ & $1.85 \%$ & 162 \\
Medolla & $40.00 \%$ & $22.22 \%$ & $22.22 \%$ & $14.44 \%$ & $0.00 \%$ & $0.00 \%$ & 90 \\
Mirandola & $29.45 \%$ & $18.00 \%$ & $14.93 \%$ & $16.36 \%$ & $10.84 \%$ & $9.00 \%$ & 489 \\
Novi di Modena & $19.59 \%$ & $38.66 \%$ & $24.23 \%$ & $8.25 \%$ & $4.12 \%$ & $4.64 \%$ & 194 \\
San Felice sul Panaro & $22.22 \%$ & $20.37 \%$ & $39.81 \%$ & $11.11 \%$ & $5.56 \%$ & $0.93 \%$ & 108 \\
\hline
\end{tabular}

Table 3: Total number of buildings and percentages with respect to the number of stories for each municipality and database.

Remembering that Dat2 consists mainly of damaged buildings, and thus percentages can be intended as referring to the most fragile building typology, Dat1 and Dat3 coherently identify 2- and 3-stories structures as the most predominant typology. If the same analysis is conducted with respect to the single municipalities shown in Fig. 10 and Fig. 11, some changes can be observed. Table 3 highlights significant differences for the considered municipalities in the distribution of the number of stories. Specifically, Dat1 consists mainly of 4- and 5-stories structures and the total count is also lower than the corresponding quantity that has been surveyed in the same municipality. Thus, when combining Dat1 and Dat2 in Dat3, this final database 
mostly consist of post-earthquake entries and the number of stories distribution reflects this, as well. However, damage scenarios are carried out relying on census data alone, which means that for some municipalities the dimension of the building stock may be underestimated. At the same time, errors may be introduced in the simulation due to misclassification of the number of stories, or of the type of construction material itself. Nonetheless, it has been shown in Table 2 that overall ratios are coherent among the different databases. It can be then said that damage scenarios produce reliable results when considering a regional scale but can lead to large misinterpretations if applied to a single municipality or limited scale. If damage scenarios aim to assess the expected fragility of single municipalities they have to be implemented starting from highly reliable and detailed data, especially with respect to those parameters that influence the chosen fragility models, such as the number of stories or construction age.

Finally, in an analogous way to what was done for masonry structures scenarios, the variability of the outcomes of the simulations is visualized in Fig. 12, disaggregated for the different fragility models considered. Damage level $\mathrm{D}_{0}$ histograms are similar for all considered models, while for other damage states results vary from model to model.
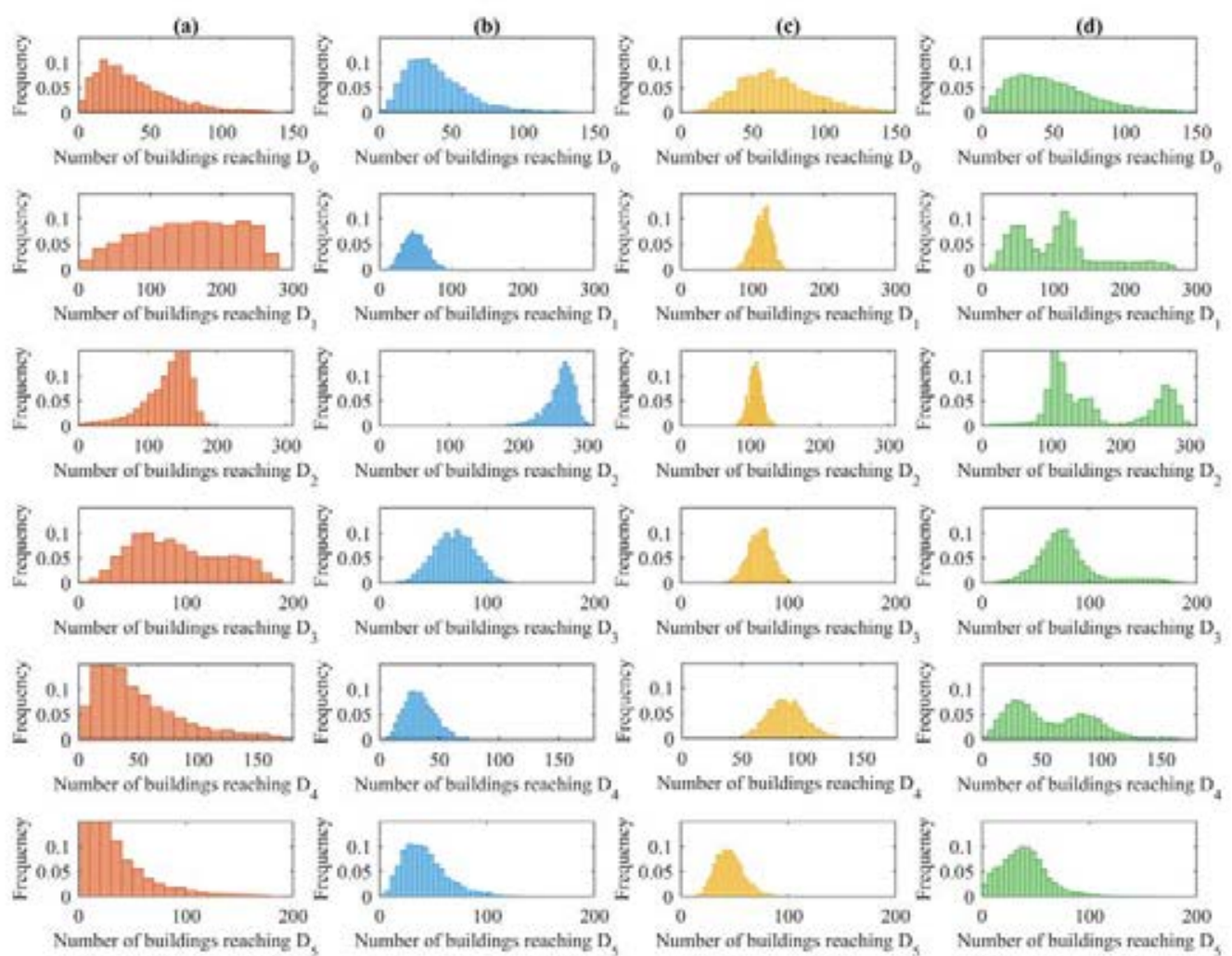

Fig. 12 - Histograms representing the distribution of the different damage levels among the 10000 simulations for the municipality of Mirandola. The a) column figures represent the contribution given by Verderame et al. fragility model [3], b) is the contribution from Salamida and Buratti's fragility model [26], while c) represent the contribution given by the model proposed by Secci [27]. Finally, the totality of the damage levels distribution accounting for all models is represented in column c) plots.

\section{CONCLUSIONS}

The present paper illustrates a framework for the simulation of seismic damage scenarios in the Emilia Romagna region, in northern Italy. First attenuation relationships are defined as well as spatial correlation models in order to estimate shake maps for the Emilia 2012 earthquakes. These tools are then employed to carry out a Monte Carlo simulation to compute damage 
scenarios for masonry and reinforced concrete residential buildings. Building stock information is obtained from the census, while fragility is estimated through models obtained from the available literature for both structural typologies. The simulated damage distribution is then compared to the observed one and results are discussed. It is derived that damage scenarios may be a powerful tool to obtain damage estimates on regional scale but may lead to overestimation or underestimation when applied to a reduced scale, such as at a single municipality level. These results are highly influenced by the quality of the building stock database (i.e. census) that introduces high uncertainties with respect to number of stories and construction material.

\section{ACKNOWLEDGEMENTS}

The financial support of the Emilia-Romagna regional agency for Civil Protection and Territorial Safety is gratefully acknowledged.

\section{REFERENCES}

[1] L. Moya, E. Mas, S. Koshimura, F. Yamazaki, Synthetic building damage scenarios using empirical fragility functions: A case study of the 2016 Kumamoto earthquake. International Journal of Disaster Risk Reduction. 31 (March), 76-84, 2018.

[2] A. Roca, X. Goula, T. Susagna, J. Chávez, M. González, E. Reinoso, A simplified method for vulnerability assessment of dwelling buildings and estimation of damage scenarios in Catalonia, Spain. Bulletin of Earthquake Engineering. 4 (2), 141-158, 2006.

[3] G.M. Verderame, P. Ricci, F. De Luca, C. Del Gaudio, M.T. De Risi, Damage scenarios for RC buildings during the 2012 Emilia (Italy) earthquake. Soil Dynamics and Earthquake Engineering. 66 (November), 385-400, 2014.

[4] M. Dolce, M. Marino, A. Masi, M. Vona,Uno scenario di danno sismico per la città di Potenza. in: X Congr. Naz. "L’ingegneria Sismica Ital., Potenza-Matera, 2001.

[5] M. Dolce, A. Kappos, A. Masi, G. Penelis, M. Vona, Vulnerability assessment and earthquake damage scenarios of the building stock of Potenza (Southern Italy) using Italian and Greek methodologies. Engineering Structures. 28 (3), 357-371, 2006.

[6] R. Spence,Earthquake Disaster Scenario Predictions \& Loss Modelling for Urban Areas. , 2007.

[7] F. Meroni, T. Squarcina, V. Pessina, M. Locati, M. Modica, R. Zoboli, A Damage Scenario for the 2012 Northern Italy Earthquakes and Estimation of the Economic Losses to Residential Buildings. International Journal of Disaster Risk Science. 8 (3), 326-341, 2017.

[8] M. Dolce, B. Borzi, F. Da Porto, M. Faravelli, S. Lagomarsino, G. Magenes, et al., Mappe di rischio per il territorio Italiano. Proceedings of the 18th Italian Conf on Earthq Eng ANIDIS. (September), SS02-21 SS02-34, 2019.

[9] L. Luzi, F. Pacor, R. Puglia, Italian Accelerometric Archive v3.0. Istituto Nazionale di Geofisica e Vulcanologia, Dipartimento della Protezione Civile Nazionale., 2019.

[10] D.M. Boore, J. Watson-Lamprey, N.A. Abrahamson, Orientation-independent measures 
of ground motion. Bulletin of the Seismological Society of America. 96 (4 A), 1502-1511, 2006.

[11] Ministero delle Infrastrutture e dei Trasporti, Aggiornamento delle «Norme tecniche per le costruzioni». Gazzetta Ufficiale Della Repubblica Italiana. (in Italian) , 1-198, 2018.

[12] K. Goda, H.P. Hong, Spatial correlation of peak ground motions and response spectra. Bulletin of the Seismological Society of America. 98 (1), 354-365, 2008.

[13] B.A. Bradley, Site-specific and spatially-distributed ground-motion intensity estimation in the 2010-2011 Canterbury earthquakes. Soil Dynamics and Earthquake Engineering. 61-62 (2014), 83-91, 2014.

[14] N. Jayaram, J.W. Baker, Correlation model for spatially distrributed ground-motion intensities. Earthquake Engineering \& Structural Dynamics. 38 , 1678-1708, 2009.

[15] C. Bruce Worden, E.M. Thompson, J.W. Baker, B.A. Bradley, N. Luco, D.J. Wald, Spatial and spectral interpolation of ground-motion intensity measure observations. Bulletin of the Seismological Society of America 108 (2), 866-875, 2018.

[16] F. Braga, M. Dolce, D. Liberatore, A statistical study on damaged buildings and an esuing review of the MSK-76 scale. 7th European Conference on Earthquake Engineering., 1982.

[17] R. Whitman,Damage probability matrices for prototype buildings., 1973.

[18] I. Ioannou, S. Bertelli, E. Verrucci, V. Arcidiacono, T. Rossetto,Empirical fragility assessment of residential buildings using data from the Emilia 2012 sequence of earthquakes. Springer Netherlands, , 2021.

[19] Italian National Statistical Institute (ISTAT). 15th Italian Population and Housing Census, 2011

[20] M. Colombi, B. Borzi, H. Crowley, M. Onida, F. Meroni, R. Pinho, Deriving vulnerability curves using Italian earthquake damage data. Bulletin of Earthquake Engineering. 6 (3), 485-504, 2008.

[21] F. Meroni, V. Petrini, G. Zonno, Distribuzione Nazionale Della Vulnerabilità Comunale. La Vulnerabilità Degli Edifici. , 105-131, 2000.

[22] D. Bindi, F. Pacor, L. Luzi, R. Puglia, M. Massa, G. Ameri, et al., Ground motion prediction equations derived from the Italian strong motion database. Bulletin of Earthquake Engineering. 9 (6), 1899-1920, 2011.

[23] Regio Decreto Legge n. 2229 del 16/11/1939. Norme per la esecuzione delle opere in conglomerate cementizio semplice od armato. G.U. n. 92 del 18/04/1940 (in Italian).

[24] M. Dolšek, P. Fajfar, Simplified non-linear seismic analysis of infilled reinforced concrete frames. Earthquake Engineering and Structural Dynamics. 34 (1), 49-66, 2005.

[25] G. Grünthal, European Macroseismic Scale 1998. in: Cah. Du Cent. Eur. Géodynamique 
Séismologie, Luxembourg, 1998.

[26] G. Salamida, N. Buratti, Fragility models for existing masonry infilled RC frames in the Emilia area. in: 8th ECCOMAS Themat. Conf. Comput. Methods, , 2021.

[27] E. Secci, Definizione di modelli di fragilità per edifici sulla base di dati sul danneggiamento relativi al terremoto dell'Aquila 2009, 2020.

[28] M. Rota, A. Penna, C.L. Strobbia, Processing Italian damage data to derive typological fragility curves. Soil Dynamics and Earthquake Engineering. 28, 933-947, 2008. 